\title{
Are Wikis and Weblogs an Appropriate Approach to Foster Collaboration, Reflection and Students' Motivation?
}

\author{
Mathias Krebs, Christian Schmidt, Michael Henninger, \\ Matthias Ludwig, and Wolfgang Müller \\ University of Education, Kirchplatz 2, \\ 88250 Weingarten, Germany \\ \{krebs, schmidt, henninger, ludwig, müller\} @ph-weingarten.de
}

\begin{abstract}
There are a few hints (e.g. PISA) that today's' German school system could be improved to prepare students for their future (professional) lives in an adequate way. To meet the requirements of today's society, education has to change to become a life-long learning process. E-Learning provides opportunities for this purpose. In this paper two studies at the University of Education Weingarten are presented, which investigate the impact of wikis and weblogs on students' learning processes. While the first one investigates the impact of weblogs on students' motivation and reflection processes, the second one concentrates on collaboration and knowledge sharing by utilizing wikis for mathematical projects.
\end{abstract}

Keywords: e-learning, social software, wikis, weblogs, motivation, reflection, collaboration.

\section{Introduction}

Our society is in flux. Frequently changing affordances, not only in professional life, require a life long learning process from today's students [1]. As a consequence, today's education system must be adapted to these new circumstances. Schools, as important instances of education and socialization, have the duty to qualify students for their future (professional) lives. Today, this means that they are confronted with the challenge to prepare them "for jobs that don't yet exist, using technologies that haven't yet been invented, in order to solve problems that we don't even know are problems yet" [2, p.2]. It is more and more doubtful, whether these goals can be reached by only applying traditional teaching methods that have been utilized in schools in the past. In the recent discussion the demand to focus on communicative and situated learning as well as on the fostering of learning communities are increasingly mentioned [3]. Here, the implementation of e-learning can facilitate designing adequate learning scenarios to impart the competences needed for the 21 st century. High hopes are particularly pinned on the new communication and presentation technologies of the social web, also referred to as Web 2.0 [4]. "Emergent Web 2.0 
concepts and technologies are opening new doors for more effective learning and have the potential to support life-long competence development" [5, p.72].

One of several activities set by the federal state Baden-Württemberg (Germany) in order to implement innovative teaching methods at school is the post-graduate colloquium on e-learning in schools as the basis for life-long learning to research the use of new e-learning concepts at schools systematically. Within this field, scientists from the Universities of Education in Ludwigsburg, Schwäbisch-Gmünd and Weingarten work together on different studies.

\section{Studies at the University of Education Weingarten}

The research group at the University of Education Weingarten focuses on the question, whether e-learning can foster collaboration, reflection, as well as students' motivation; and in which way this can be encouraged. Thereby, they highlight social software, because it can connect people with the same interests. Because learning is a social process it is recommendable to also use these tools that "have [...] been associated with collaborative activities, knowledge sharing, reflection, debate, and facilitation of communities of practice" [6, p.1] also for this purpose.

In the following the theoretical framework as well as the research design and first results of two studies are presented. While the first study examines the use of weblogs at school and its impact on students' motivation and reflection processes, the second one concentrates on collaboration and knowledge sharing by utilizing wikis for mathematical projects.

\subsection{Weblogs at School - A Tool to Foster Self-determined and Motivated Learning as Well as Reflection?}

Even though latest media studies [7] show that blogging as well as blog commenting has declined in popularity among teens and young adults during the last years, there still exists a gap between the use of ICT by students in their spare time and the use of such technologies at school.

First explorative studies and best practice reports - primarily in the context of higher education - came to the result that weblogs are well suited to support a selfdetermined learning process as well as to increase students' motivation and reflection processes $[8,9,10]$. Motivation and reflection are both key factors for a successful learning process and their impact on learning results is proofed several times in the field of learning sciences [11]. In the follow sections both constructs are specified before the research questions and the research design are presented.

\subsubsection{Motivation}

To be motivated in general means to be activated toward a positive valuated target. In the course of time diverse approaches and theories were developed in the field of motivation research. These can be categorized roughly by the source of activation energy. Most notably, three different energy sources can be distinguished: (1) physiological needs (e.g. instincts and drives), (2) emotions and (3) psychological needs [12]. 
One theory that is often mentioned regarding weblogs and motivation [13] is the self-determination theory of motivation by Deci and Ryan [14]. In that, the authors distinguish between two kinds of motivation: intrinsic and extrinsic motivation. "Intrinsic motivation is defined as the doing of an activity for its inherent satisfactions rather than for some separable consequence" $[15$, p.56) whereas "extrinsic motivation is construct that pertains whenever an activity is done in order to attain some separable outcome" [15, p.60]. Intrinsic motivated actions are always self-determined. This does not mean that extrinsic motivated action is invariantly non-autonomous. It can vary greatly in the degree to which it is autonomous. People can internalize and integrate external values and behavioural regulation into their own, so that they act extrinsic motivated but self-determined to reach a certain goal. For the intrinsic as well as for the extrinsic motivation the satisfaction of two psychological needs is necessary, the need to feel competent and the need to feel autonomous. For the selfdetermined extrinsic motivation Deci and Ryan amend that the person must feel a sense of relatedness.

In the context of learning, former research showed that students who act in a selfdetermined way are more willing to engage cognitively in the learning content and to assimilate the stuff more deeply [16]. Thus, one goal of instructional design should be to foster a self-determined learning process by designing learning scenarios which support the satisfaction of the three psychological needs mentioned above. Here, weblogs can help in different ways.

The chronological collection of posts reveals the gain of competence to the learner (internal perspective). Furthermore, writing a weblog affords the chance that the students' knowledge, thoughts and abilities are noticed and at best even honored, e.g. through commentaries or references, by others (external perspective). Both should have a positive impact of feeling competent.

The sense of being related to other persons can be fostered since weblogs offer the possibility to link them among each other. Thus, a decentrally organized and open community develops, which allows them to socialize and to maintain contacts.

Weblogs also can enhance the feeling of acting autonomously in two ways. Firstly, they are a way of self expression. The student decides on the individual design of his blog as well as on the topics he blogs about and by this how he will present himself to the readers. Secondly, weblogs are expected to initiate reflection processes and reflection is expected as a kind of antidote against dwindling of autonomy [17].

\subsubsection{Reflection}

Besides motivation, reflection is a second important psychological construct for learning. The most popular approaches to reflection are the works of Dewey [18], Vgotsky [19] and Schön [20]. Based on the findings of these authors reflection can be defined as "a process during which a person pays attention to a problem, evaluates this problem on the background of a previously set goal and of his/her past experiences, generates options for action, relates the expectable outcomes of these options to the present situation, and makes decisions for future actions with the aim of solving the problem" [21, p.56].

In the last years Web 2.0 technologies were increasingly expected as a way to foster reflection during learning processes. Regarding weblogs these assumptions are based on previous research in the field of learning journals [22]. The results suggest 
that writing an entry already initiates reflection processes and leads to a deeper assimilation of the learning contents. The learner has to think about his learning process, organize his thoughts and externalize them as texts or artefacts. All these processes are expected to support reflection. While the verbalization of individual thoughts is also necessary to create a blog post, weblogs furthermore provides the opportunity to integrate peers in the reflection process. They can comment the entries and participate in discussions. By this, convergent perspectives of the learning content as well as different options for further action are shown. This can also initiate a rethinking and reflection process. Thus, the possibility to leave comments supports cognitive and metacognitive strategies during the learning process and leads to a deeper learning [23]. The results of an empirical study by Du and Wagner [24] indicate that successfully blogging can be a predictor for the success in a course or an exam. All in all, weblogs seems to have the potential to foster a more self-determined and reflected way of learning. In our study we want to figure out whether students are able to unfold this potential.

\subsubsection{Research Questions and Study Design}

So far, the explanations point out that the use of weblogs at school seems to be a promising tool to foster self-determined and motivated learning as well as reflection. But at the moment there is a lack of empirical evidence for these assumptions because of the used researched methods. By using a quasi experimental research design as well as method triangulation (see figure 1), the aim of this project is to find empirical sustainable answers to the following research questions:

1. What impact has the use of weblogs at school on the parameters of the selfdetermination theory by Deci and Ryan and mediated by that on students' motivation?

2. Can conclusions be drawn from the use of weblogs at school to students' reflection processes?

3. What impact has the use of weblogs at school on students' learning outcome?

The study is scheduled for the end of the current school year. It will start by collecting data about the class climate, students' interest in the subject, students' interest in Web 2.0 tools, students' media competence, teachers' behaviour and teachers' interest. Therefore a standardized questionnaire is used. These data are used as control variables and based on these, matched samples are constructed. In a next step the classes are divided in a control and two experimental groups. The control group design has been chosen to research whether expected effects are really du to utilization of weblogs or if other aspects have a greater impact on the variables. After training the teacher and students of the experimental groups in using the weblog software, they will write a weblog in addition to their lessons for four weeks. While the control group will be taught without weblogs, in the first experimental group every student will write his own weblog and in the second one a class weblog will be used. At the beginning and at the end of this phase, again data will be collected with a standardized questionnaire that contained items related to self-determination and motivation as well as to students' reflection. Afterwards, the teachers and a sample of students of 
the experimental classes will be interviewed to validate the results, especially concerning the reflection processes. Furthermore, all blog posts will be quantitatively and qualitatively analyzed.

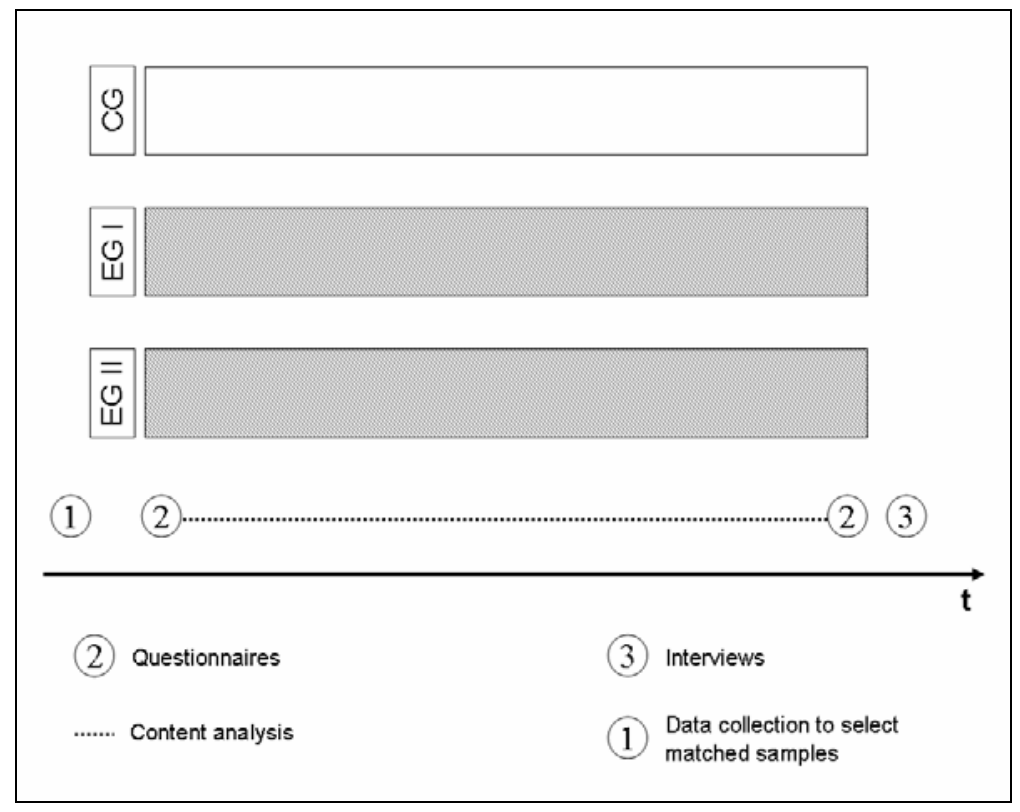

Fig. 1. Research design of the main study

On the one hand it could be doubted that meaningful results will be found after using weblogs for only four weeks. On the other hand would be problematic to do field research in classes for a longer period of time. Thus, an explorative pilot study was done at the University of Education Weingarten last year [25]. Students, studying "Media and Education Management", used weblogs in addition to their media law classes. A panel study with four measuring times at intervals of approximately four weeks revealed that the parameters of self-determination theory as well as the constructs of interest and motivation are time stable. Over all measuring times there could not be found any significant differences in the answers of the course. Thus, a four week study at school should be sufficient to answer the research questions mentioned above and it definitely facilitates to find teacher for cooperation.

On the conference first results of this project will be presented and put up for discussion.

\subsection{Utilizing Wikis for Collaboration and Knowledge Sharing in Mathematical Projects}

Duffy and Bruns [26] outline different uses of wikis. Among others, they mention that a wiki can be used for acting as ongoing documentation of student's work and to add 
summaries of their thoughts and building collaborative and annotated content as well as linked network of resources.

A considerable amount of examples on the application of wikis for learning and teaching exist [27, 28]. Most concerns how wikis can support writing [29, 30, 31]. To improve academic writing, Wheeler and Wheeler [32] used a wiki. They come to the conclusion that their "findings indicate that most students raised their skill level in writing as a result of using the Wiki space" [33, p.1]. But wikis are also used in other subjects. For example, Notari [34] used a wiki in a classroom for learning biology and highlights the importance of developing a "communication and comment culture".

Himpsl [35] provides different examples on how to apply wikis in schools. For example, he used wikis to collect information and relevant links for a specific learning objective, recording of material in brainstorming sessions, and wiki-based WebQuests. For example a Web-Quest was done with the topic "Golden Section". Small projects were also performed with a wiki.

Although, as seen, wikis are used in education experiences for learning Mathematics, project-based fundamental surveys about unfolding their potential for collaboration, communication and discussions as well as for reflecting about content are missing.

As a consequence, we used a wiki in a seminar at University of Education Weingarten (Germany). Students in "Mathematics and Education on project-based Math learning" were given the task to use a wiki for conceptualizing and elaborate own mathematical projects beyond regular lectures [36].

Based on the wiki's page history mechanism, it was possible to trace and analyze the development process of individual pages in some detail. The analysis revealed that in fact the process of writing articles was rather cooperative than collaborative: students divided their tasks into different parts and worked rather independently and individually. Collaboration in terms of iterative editing and refining of content in the wiki by different students as well as discussions in the wiki took place only very seldom.

In a second study we developed a concept to apply wiki-based collaboration in German middle school classes [37]. Here, the idea was to foster collaboration and discussions in math classes using this technology. In this setting, students from different schools were using a wiki for a defined project work in a period of one month. Here, a project group consisted of two to four students, each from a different class from different schools (see figure 2).

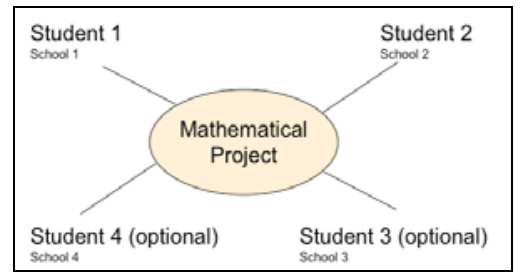

Fig. 2. Composition of a project team

A personal face-to-face meeting of participating student group members was scheduled for the project's kick-off meeting and final project presentation only. Thereby, students had to utilize the wiki during the virtual project phase to figure out 
strategic procedures and approaches on how to solve mathematical problems including how to do calculations. All in all, there were six project groups arranged, while students from three project groups discussed and commented mathematical procedures or calculations of group members.

The experiment revealed that collaboration in terms of that content was corrected (edited and deleted) inline took place in only a few exceptional cases. Rather, all students created and wrote their contributions linearly from top to bottom: all project groups were adding and refining content in a way that they just added content at the bottom of the wiki page (article) or discussion page.

Students used the wiki infrastructure to communicate and to place questions when contributions from other students introduced some procedures and calculations that were unclear to them.

It is interesting to mention that student groups to some extent exhibited the habit of signing new contributions to articles with signatures in terms of login name and timestamp. Apparently, information on the current state of the article, including the last contributor and last date and time of change were important for them. Most probably not being aware of the versioning feature of wikis, students invented their own strategy. So, students could see the progress of the project at once and had not to use the versioning feature of the wiki.

The way students utilized the wiki for refining content and asking questions indicates that some students reflected on the subject as well as on the content, created by group members. As one example, students of the project team with the question "How much math teachers are recommended in Germany?" tried to figure out the mathematical procedure together. There, one student asked which facts were needed for the mathematical calculation (e.g. number of students of a school, number of classes, math teaching load ...) and asked his team to eliminate unimportant facts and add facts, which were not listed by him. Further, this group apparently actively tried to understand provided material and explanations of other group members by asking questions. We think that in this situation students had to externalise their thoughts due to concretising procedures and answering questions. In another project, students discussed different ways to solve the question "Has a 21-gear bicycle really 21 different gears?" First, one student tried to do some multiplication stuff. Due to discussions with group members and the tutor, which gave strategic hints, he got the right procedure and explained it at the final presentation. However, the student had technical deficits to illustrate his result as a table in the wiki.

In this case we conclude that the student reflected on mathematical content and initiated rethinking. In fact, this is exactly one of the major goals and an important aspect of motivation in math classes today.

The project is ongoing, and we are currently investigating with larger user groups wheather our first results can be confirmed. Also, we would like to identify in some more detail how collaborative authoring of content can be promoted.

\section{Summary and Outlook}

In the last decades the dispersion and increasing impact of the internet and ICT on our social and professional environments has confronted education systems with new 
challenges. Social software, mobile devices and ubiquitous computing are just some of the newest examples for the still ongoing changes in our every day life. Thus, it is mandatory for schools to adapt their learning methods to these developments. Otherwise they run risk to loose their state as most important institutions for socialization and education.

First best practice examples suggest that weblogs and wikis are a promising way to improve students' learning and to impart their 21 st century skills at the same time. But at the moment these assumptions are at the best hypotheses. Empirical research, like both studies described in this paper, is absolutely necessary. Not only to proof the potential of these tools for particular learning scenarios, but also to effectively implement them in general education. In the long run it will be inevitable to change the way we teach today students without missing the aim to prepare them for their future (professional) lives.

\section{Acknowledgements}

The presented studies are both part of the comprehensive post-graduate colloquium on e-learning in schools as the basis for life-long learning, funded by the Ministry of Science, Research and Arts of the federal state Baden-Württemberg, Germany.

\section{References}

1. Commission of the European Communities: A Memorandum on Lifelong Learning (2000), http: / / www. bologna-berlin2003.de/pdf/MemorandumEng.pdf (15.02.2010)

2. Fischer, K.: Did you know? (2006), http://www.lps.k12.co.us/schools/ arapahoe/fisch/didyouknow/didyouknowtext.pdf (15.02.2010)

3. Weicht, W.: Manifest Schule 2.0 (2009), http: / /blog.schulezweipunktnull.de/2009/05/ manifest-schule-20/(13.05.2009)

4. O'Reilly, T.: What Is Web 2.0. Design Patterns and Business Models for the Next Generation of Software (2005), http: / / oreilly.com/web2/archive/what-is-web20.html (21.01.2010)

5. Klamma, R., Chatti, M.A., Duval, E., Hummel, H., Hvannberg, E.H., Kravcik, M., Law, E., Naeve, A., Scott, P.: Social software for life-long learning. Journal of Educational Technology and Society 10, 72-83 (2007), http: / / www. ifets. info/journals / 10_3/6.pdf (15.02.2010)

6. Sevelj, M.: All eLearning in the same basket? Challenging a social constructivist, fit for all'. Paper Presented at The Distance Education Association of New Zealand Biennial Conference, July 3-5. Auckland University of Technology (AUT), Auckland (2006)

7. Lenhart, A., Purcell, K., Smith, A., Zickuhr, K.: Social Media \& Mobile Internet Use Among Teens and Young Adults (2010), http://pewresearch.org/pubs/ 1484/social-media-mobile-internet-use-teens-millennialsfewer-blog (15.02.2010)

8. Pullich, L.: Weblogs als Lernjournale. Kommunikation und Reflexion mit Weblogs im Rahmen akademischer Abschlussarbeiten. IfBM.Impuls - Schriftenreihe des Instituts für Bildungswissenschaft und Medienforschung (2007) 
9. Spannagel, C.: Eine Weblog-Umgebung zur Förderung selbstbestimmt motivierten Lernens. In: Rensing, C., Rößling, G. (eds.) Procedings der Pre-Conference Workshops der 5. e-Learning Fachtagung Informeatik DeLFI 2007, Siegen, Logos, Berlin, pp. 11-18 (September 2007)

10. Christen, A., Hofmann, M., Obendrauf, M.: Portfolioarbeit mit einem eLernreisebuch und einem ePortfolio auf einem Blog mit Studierenden im 1. Semester an der Pädagogischen Hochschule Rorschach (2006), http://metablog.phrblog.kaywa.ch/files/ vorstudie-eportfolio-27-08-06.pdf (14.05.2009)

11. Sawyer, R.K.: The Cambridge Handbook of the Learning Sciences. Cambridge University Press, New York (2006)

12. Rheinberg, F.: Motivation, 7th edn. Kohlhammer, Stuttgart (2008)

13. Reinmann, G.: Persönliches Wissensmanagement. Einführung und Denkanstöße (2008), http: / / gabi-reinmann. de//wp-content/uploads / 2008/04/ vortrag_ingolstadt_april_08.pdf (13.05.2009)

14. Deci, E.L., Ryan, R.M.: Die Selbstbestimmungstheorie der Motivation und ihre Bedeutung für die Pädagogik. Zeitschrift für Pädagogik 39, 223-238 (1993)

15. Ryan, R.M., Deci, E.L.: Intrinsic and Extrinsic Motivations: Classic Definitions and New Directions. Contemporary Educational Psychology 25, 54-67 (2000)

16. Pintrich, P.R., Schrauben, B.: Student's Motivational Beliefs and Their cognitive Engagement in Classroom Academic Tasks. In: Schunk, D.H., Meece, J.L. (eds.) Student Perceptions in the Classroom, pp. 149-183. Lawrence Erlbaum, Hillsdale (1992)

17. Reinmann, G., Bianco, T.: Knowledge Blogs zwischen Kompetenz, Autonomie und sozialer Eingebundenheit (2008), http://www.imb-uni-augsburg.de/files/ Arbeitsbericht_17.pdf (15.02.2010)

18. Dewey, J.: How we think. In: Boydston, J.A. (ed.) John Dewey: The later works, 19251953, vol. 8, pp. 105-352. Southern Illinois University Press, Carbondale (1933/1986)

19. Vygotsky, L.S.: Mind in society: The development of higher psychological processes. Harvard University Press, Cambridge (1978)

20. Schön, D.A.: The reflective practitioner. Jossey-Bass, San Francisco (1983)

21. Henninger, M., Mandl, H.: Training soft skills with software. Fostering reflection in the training of speech-receptive action. In: Frey, D., von Rosenstiel, L., Mandl, H. (eds.) Knowledge and Action, pp. 53-86. Springer, New York (2006)

22. Moon, J.A.: Learning Journals: A Handbook for Academics, Students and Professional Development. Routledge Falmer, London (2004)

23. Nückles, M., Renkl, A., Fries, S.: Wechselseitiges Kommentieren und Bewerten von Lernprotokollen in einem Blended Learning Arrangement. Unterrichtswissenschaft 33, 227 243 (2005)

24. Du, H.S., Wagner, C.: Learning with Weblogs: An Empirical Investigation. In: Proceedings of the 38th Hawaii International Conference on System Sciences, vol. 7b (2005)

25. Schmidt, C., Henninger, M.: Der Einsatz von Weblogs in der Hochschullehre und seine Auswirkung auf die Paramter der Selbstbestimmungstheorie nach Deci und Ryan im zeitlichen Verlauf. Presentation at 73. Tagung der Arbeitsgruppe für Empirische Pädagogische Forschung (AEPF), Bochum, Germany (2009)

26. Duffy, P., Bruns, A.: The use of blogs, wikis and RSS in education: A conversation of possibilities. In: Proceedings of the Online Learning and Teaching Conference 2006, Brisbane (2006), http: / / eprints.qut .edu.au/5398/1/5398.pdf (15.02.2010)

27. Schwartz, L., Sharon, C., Cossarin, M., Rudolph, J.: Educational Wikis: Features and selection criteria. International Review of Research in Open and Distance Learning 5 (2004), http: / /www.irrodl.org/index.php/irrodl/article/view/163/692 (15.02.2010) 
28. Honegger, B.D.: Wiki und die starken Lehrerinnnen. In: Friedrich, S. (ed.) Unterrichtskonzepte für informatische Bildung, Köllen, Bonn, pp. 173-183 (2005)

29. Rick, J., Guzdial, M., Carroll, K., Holloway-Attaway, L., Walker, B.: Collaborative learning at low cost: CoWeb use in English composition. In: Proceedings of Computer Support for Collaborative Learning Conference, Boulder, CO, USA, January 7-11, pp. 435-442 (2002)

30. Hampel, T., Selke, H., Vitt, S.: Deployment of simple user-centered collaborative technologies in educational institutions - Experiences and requirements. In: Proceedings of the 14th IEEE International Workshops on Enabling Technologies: Infrastructure for Collaborative Enterprise (WETICE 2005), Linköping, Sweden, June 13-15, pp. 207-214 (2005)

31. Bruns, A., Humphreys, S.: Wikis in teaching and assessment: The M/Cyclopedia project. In: Proceedings of the 2005 International Symposium on Wikis, San Diego, CA, USA, October 16-18, pp. 25-32 (2005)

32. Wheeler, S., Wheeler, D.: Evaluating Wiki as a tool to promote quality academic writing skills (2007), http://telearn.noe-kaleidoscope.org/warehouse/158_ Final_Paper_(00168) 0v1.pdf (15.02.2010)

33. Wheeler, S., Wheeler, D.: Using wikis to promote quality learning outcomes in teacher training. Learning, Media and Technolog 34, 1-10 (2009)

34. Notari, M.: How to use a wiki in education: wiki based effective constructive learning. In: Proceedings of the 2006 International Symposium on Wikis, Odense, Denmark (2006), http: / / www.wikisym.org/ws2006/proceedings/p131.pdf (15.02.2010)

35. Himpsl, K.: Wikis im Blended Learning: Ein Werkstattbericht. Werner Hülsbusch, Boizenburg (2007)

36. Krebs, M., Ludwig, M.: Math learning with Wikis. In: The 9. International Conference on Technology in Mathematics Teaching (ICTMT 9), Metz (2009),

http: / / www . ictmt9. org/contribution.php? id=84\&lang=en (15.02.2010)

37. Krebs, M., Ludwig, M., Müller, W.: Learning Mathematics Using a Wiki. Procedia Social and Behavioral Sciences 2(2), 1469-1476 (2010) 